\title{
Spontaneous in vitro and in vivo interaction of (-)-oleocanthal with glycine in biological fluids: Novel pharmacokinetic markers
}

Lucy I Darakjian, ${ }^{1 \#}$ Aimilia Rigakou, ${ }^{2 \#}$ Andrew Brannen, ${ }^{1}$ Mohammed H Qusa, ${ }^{3}$ Niki Tasiakou, ${ }^{2}$ Panagiotis Diamantakos, ${ }^{2}$ Miranda N Reed, ${ }^{1,4}$ Peter Panizzi, ${ }^{1}$ Melissa D Boersma, ${ }^{5}$ Eleni Melliou, ${ }^{2}$ Khalid A El Sayed, ${ }^{3}$ Prokopios Magiatis ${ }^{* 2}$ Amal Kaddoumi ${ }^{* 1,4}$

\# Equal contribution

${ }^{1}$ Department of Drug Discovery and Development, Harrison School of Pharmacy, Auburn University. Auburn, AL 36849, United States.

2 Department of Pharmacy, Laboratory of Pharmacognosy and Natural Products Chemistry, National and Kapodistrian University of Athens, Greece.

${ }^{3}$ School of Basic Pharmaceutical and Toxicological Sciences, College of Pharmacy, University of Louisiana at Monroe, 1800 Bienville Drive, Monroe, LA 71201, United States.

${ }^{4}$ Center for Neuroscience Initiative, Auburn University, Auburn, AL, United States.

${ }^{5}$ Department of Chemistry and Biochemistry, Auburn University, Auburn, Alabama 36849, United States.

\section{Corresponding Authors}

* Prokopios Magiatis, Ph.D. Department of Pharmacy, Laboratory of Pharmacognosy and Natural Products Chemistry, National and Kapodistrian University of Athens, Greece. Email: magiatis@pharm.uoa.gr

* Amal Kaddoumi, Ph.D. Department of Drug Discovery and Development, Harrison School of Pharmacy, Auburn University. 720 S Donahue Dr. Auburn, AL, 36849. Email: kaddoumi@auburn.edu 
Supporting Information

Table of Contents

Figure S1. Typical chromatograms for oleocanthal in acetonitrile solution (A), and in water/acetonitrile mixture (B). Structures of oleocanthal and oleocanthadiol are also shown. (C) Mass spectrum of oleocanthal $\mathrm{m} / \mathrm{z} 305.1377\left(\mathrm{M}^{+}\right)$, oleocanthadiol $\mathrm{m} / \mathrm{z}$ $322.1646[\mathrm{M}]^{+}$and $327.1198[\mathrm{M}+\mathrm{Na}]^{+}$. (D) Photodiode array derived UV spectra of oleocanthal and derived compounds.

Figure S2. $\quad{ }^{1} \mathrm{H}-\mathrm{NMR}$ spectra of the reaction between oleocanthal and an equimolar mixture of glycine, lysine and alanine at different time points in $\mathrm{D}_{2} \mathrm{O}$. Oleoglycine (3a,b) is formed as shown by comparison with the upper spectrum obtained after reaction of oleocanthal only with glycine only.

Figure S3. $\quad{ }^{1} \mathrm{H}{ }^{1} \mathrm{H}-\mathrm{COSY}$ spectrum of oleoglycine (3a,b) in $\mathrm{D}_{2} \mathrm{O}$.

Figure S4. $\quad{ }^{1} \mathrm{H}{ }^{13} \mathrm{C}-\mathrm{HMBC}$ spectrum of oleoglycine (3a,b) in $\mathrm{D}_{2} \mathrm{O}$.

Figure S5. HSQC-DEPT spectrum of oleoglycine (3a,b) in $\mathrm{D}_{2} \mathrm{O}$.

Figure S6. $\quad{ }^{1} \mathrm{H}{ }^{15} \mathrm{~N}-\mathrm{HMBC}$ spectrum of oleoglycine (3a,b) in $\mathrm{D}_{2} \mathrm{O}$.

Figure S7. $\quad{ }^{1} \mathrm{H}-\mathrm{NMR}$ spectra of the reaction between oleocanthal $(100 \mu \mathrm{g})$ and glycine $(\mathrm{x} 300)$ at different temperatures $\left(25\right.$ and $37^{\circ} \mathrm{C}$ ) in $\mathrm{D}_{2} \mathrm{O}$ after $10 \mathrm{~min}$. The aldehyde peak has almost completely disappeared at $37^{\circ} \mathrm{C}$ significantly faster than at $25^{\circ} \mathrm{C}$.

Figure S8. $\quad{ }^{1} \mathrm{H}-\mathrm{NMR}$ spectra of the reaction between oleocanthal and glycine (x5) at different time points in $\mathrm{D}_{2} \mathrm{O}$ at $\mathrm{pH}=2$.3. $\alpha$ and $\beta$-oleoglycine are observed based on the two proton peaks at 8.22 and $8.29 \mathrm{ppm}$. Their formation is almost completed within 90 to $180 \mathrm{~min}$.

Figure S9. $\quad{ }^{1} \mathrm{H}-\mathrm{NMR}$ spectra of the reaction between oleocanthal and glycine (x5) at different time points in $\mathrm{D}_{2} \mathrm{O}$ at $\mathrm{pH}=8.5$. The alkaline $\mathrm{pH}$ is detrimental for the formation of oleoglycine as observed from the peak at $8.22 \mathrm{ppm}$. 
A

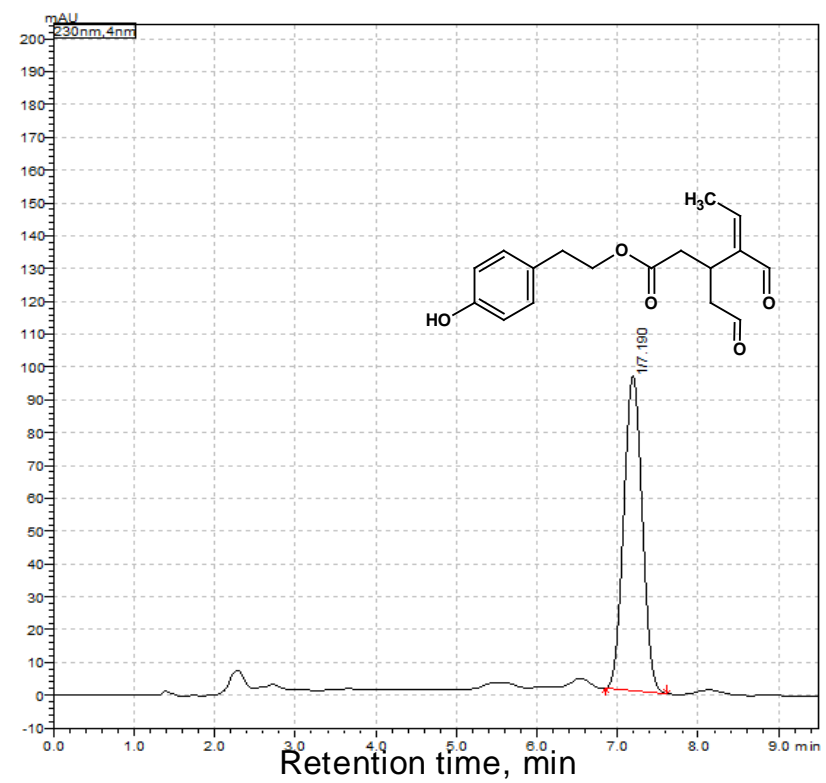

B

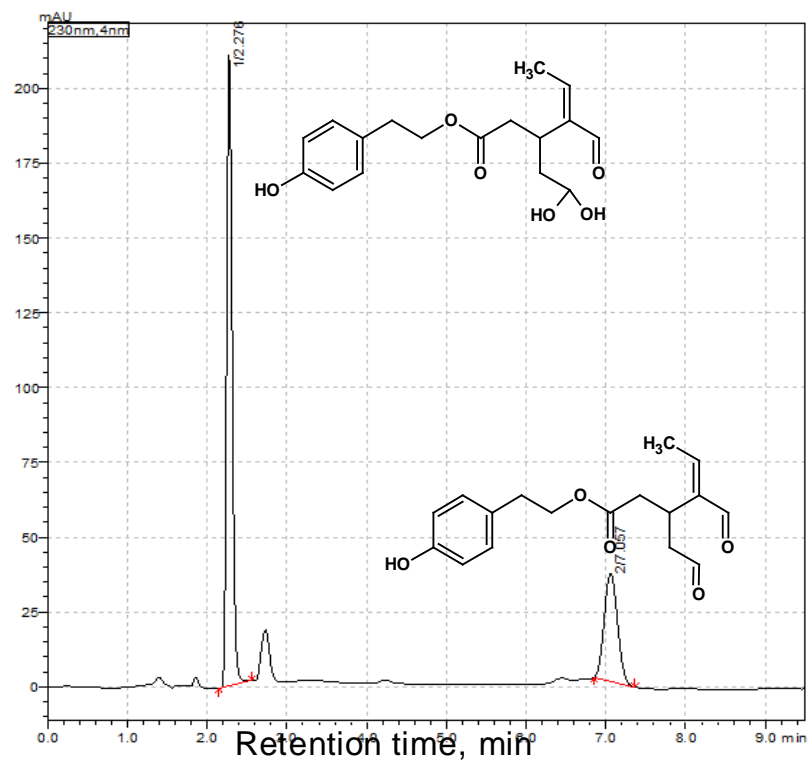

C

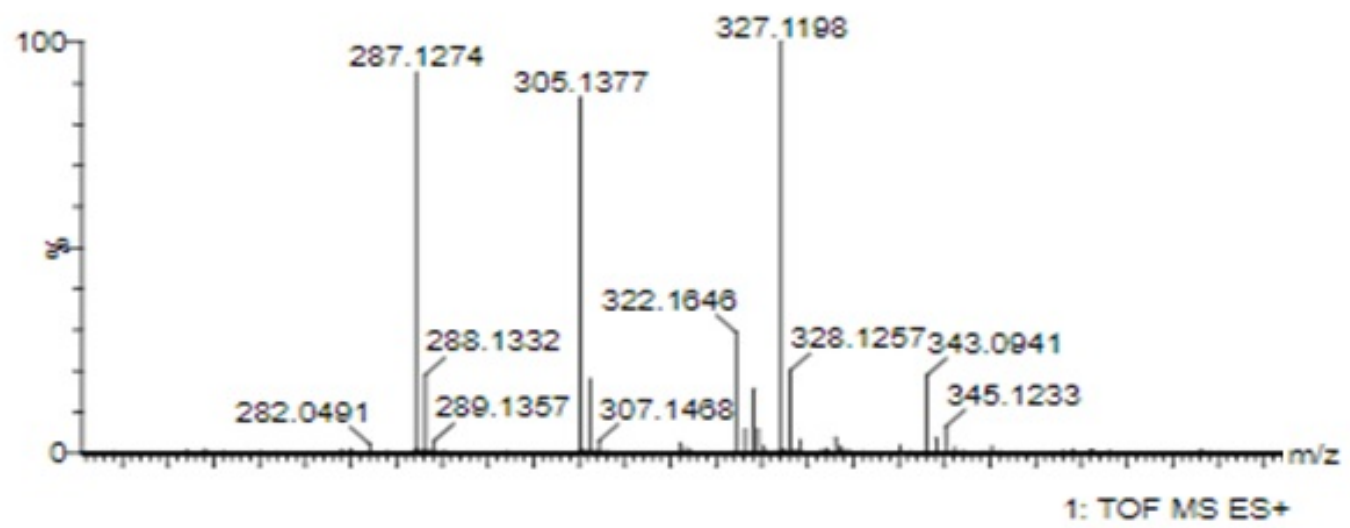



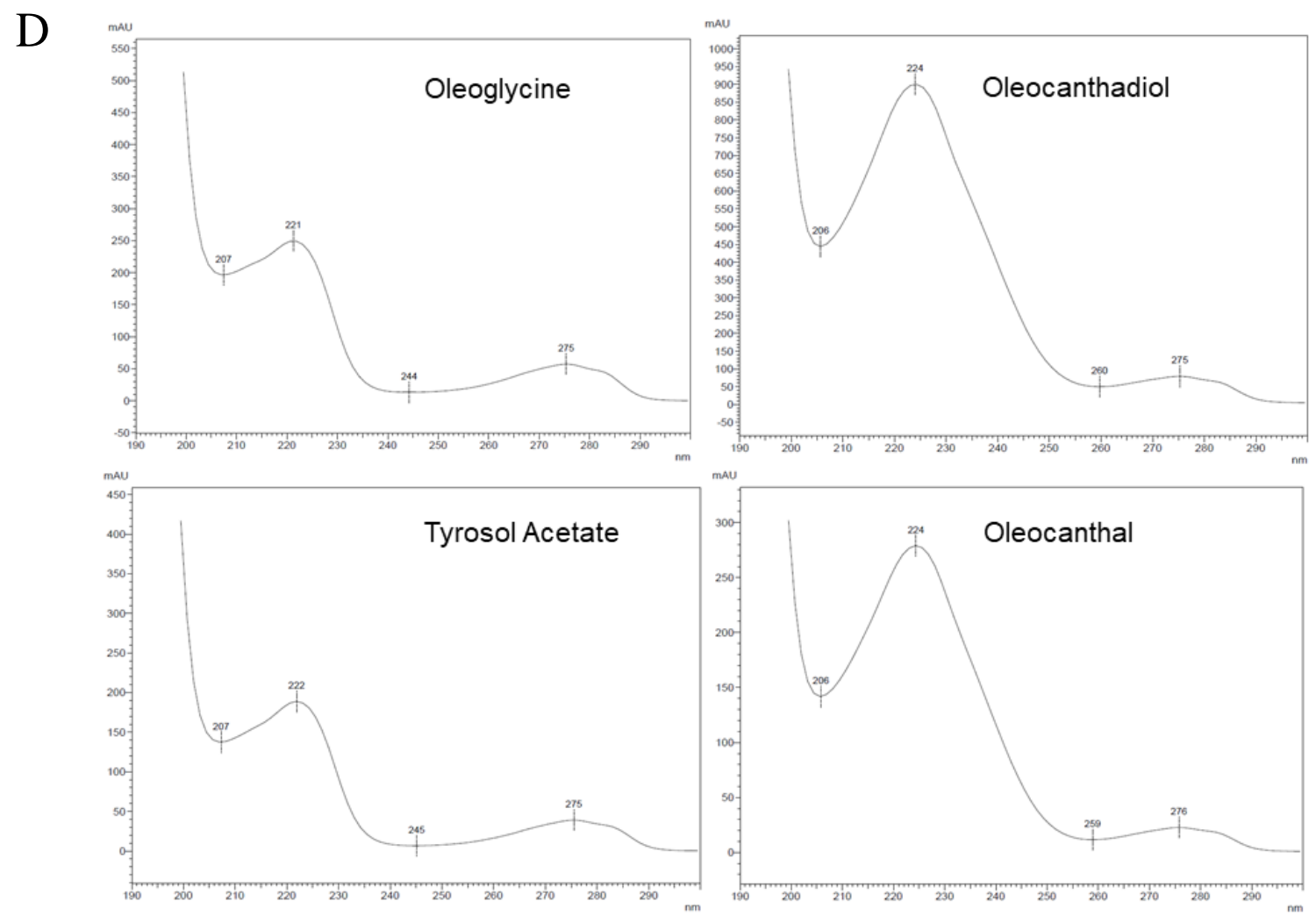

Fig. S1. Typical chromatograms for oleocanthal in acetonitrile solution (A), and in water/acetonitrile mixture (B). Structures of oleocanthal and oleocanthadiol are also shown. (C) Mass spectrum of oleocanthal $\mathrm{m} / \mathrm{z} 305.1377\left(\mathrm{M}^{+}\right)$, oleocanthadiol $\mathrm{m} / \mathrm{z} 322.1646\left(\mathrm{M}^{+}\right)$and 327.1198 (M+Na). (D) Photodiode array derived UV spectra of oleocanthal and derived compounds. 


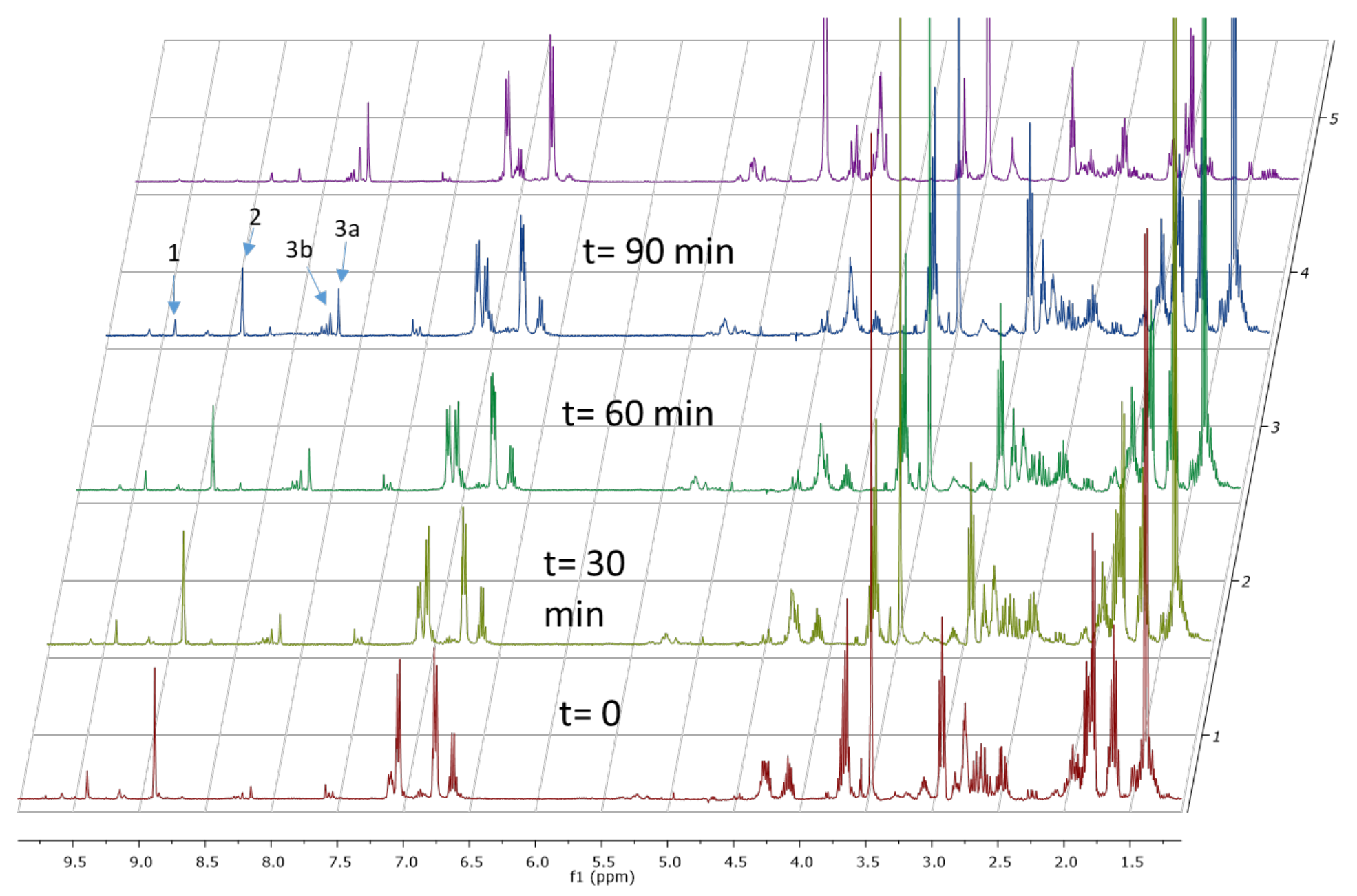

Fig. S2. ${ }^{1} \mathrm{H}-\mathrm{NMR}$ spectra of the reaction between oleocanthal and an equimolar mixture of glycine, lysine and alanine at different time points in $\mathrm{D}_{2} \mathrm{O}$. Oleoglycine (3a,b) is formed as shown by comparison with the upper spectrum obtained after reaction of oleocanthal only with glycine only. 


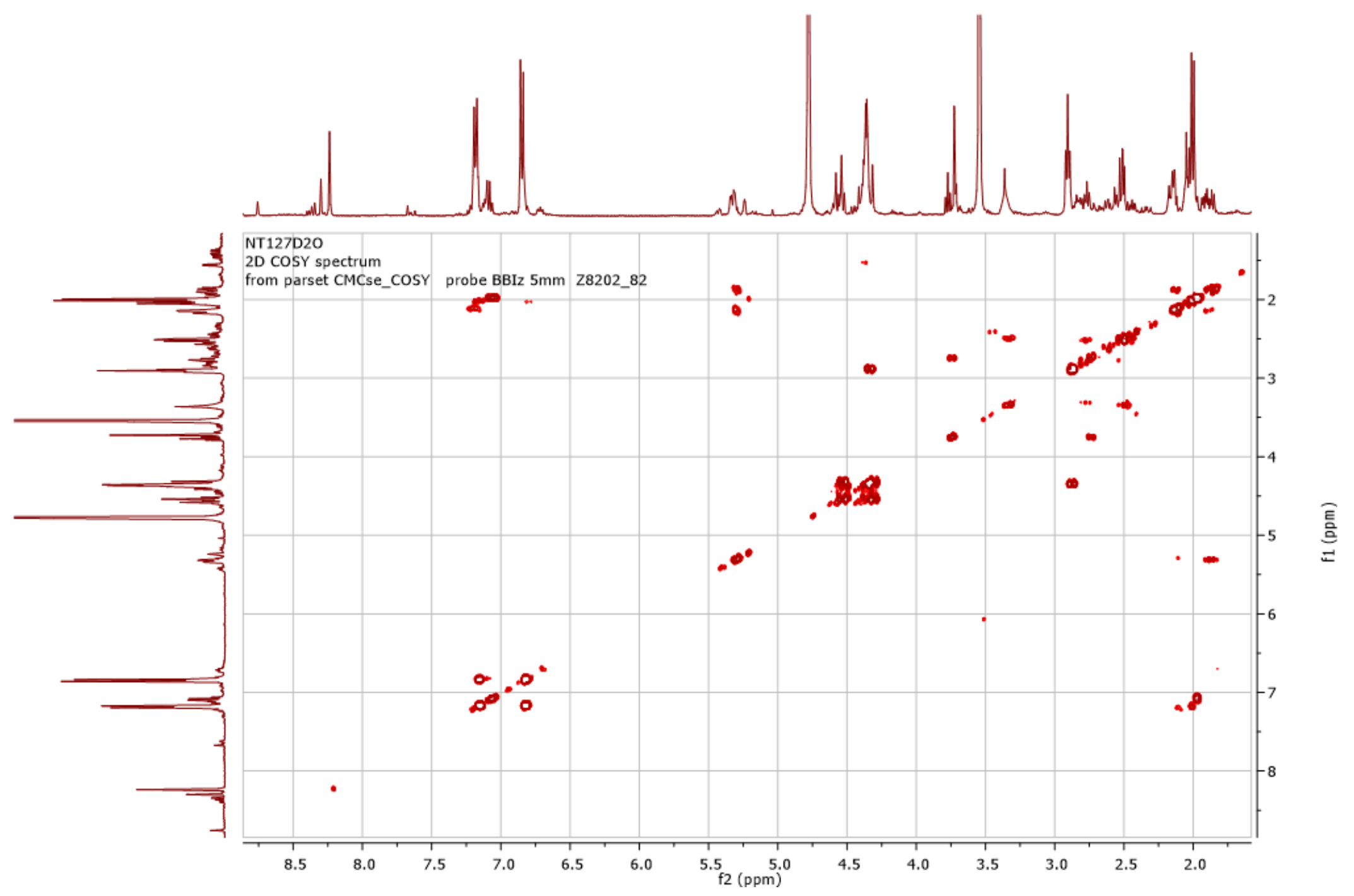

Fig. S3. ${ }^{1} \mathrm{H}{ }^{1} \mathrm{H}-\mathrm{COSY}$ spectrum of oleoglycine (3a,b) in $\mathrm{D}_{2} \mathrm{O}$. 


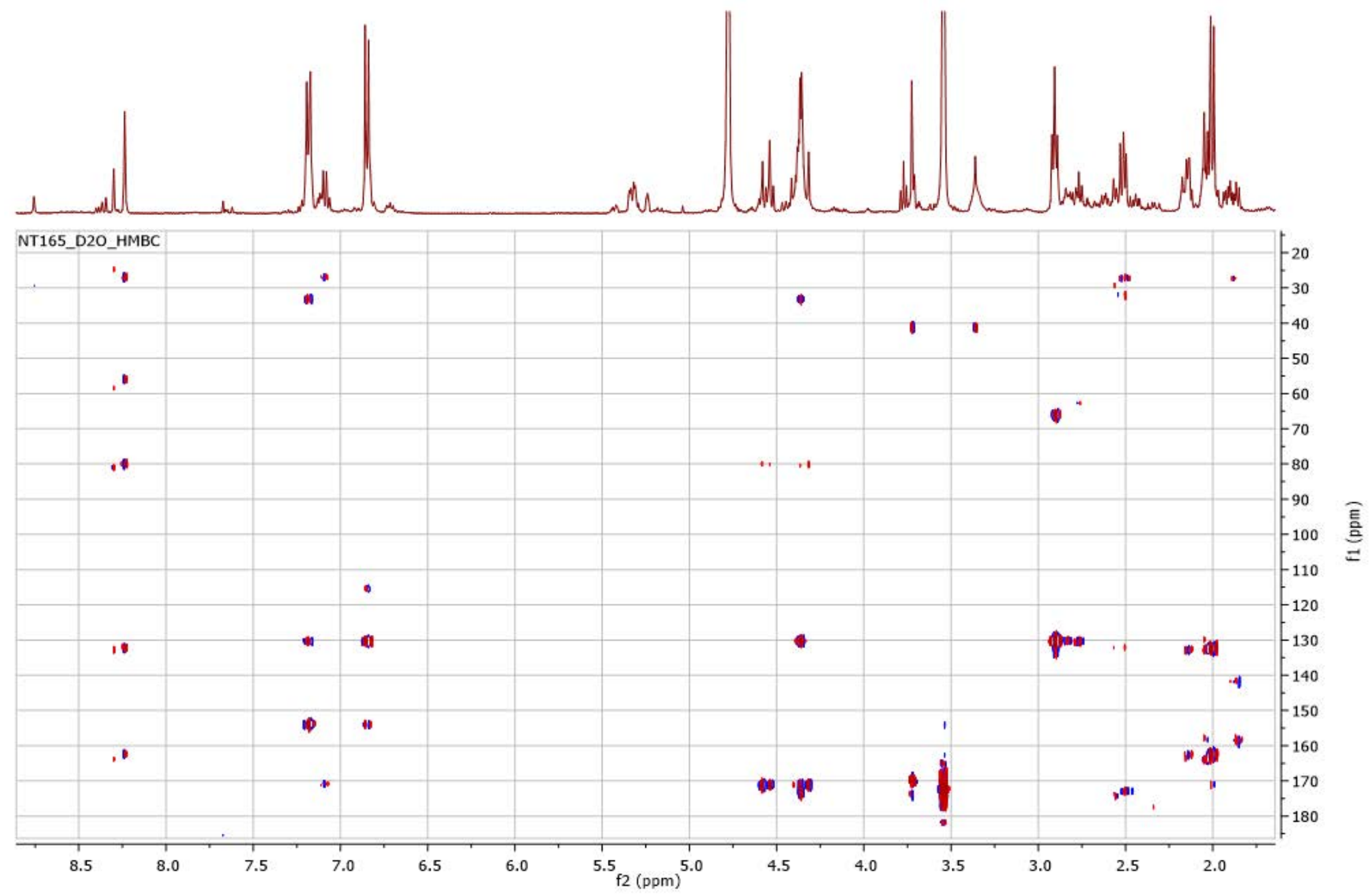

Fig. S4. ${ }^{1} \mathrm{H}^{13} \mathrm{C}-\mathrm{HMBC}$ spectrum of oleoglycine (3a,b) in $\mathrm{D}_{2} \mathrm{O}$. 

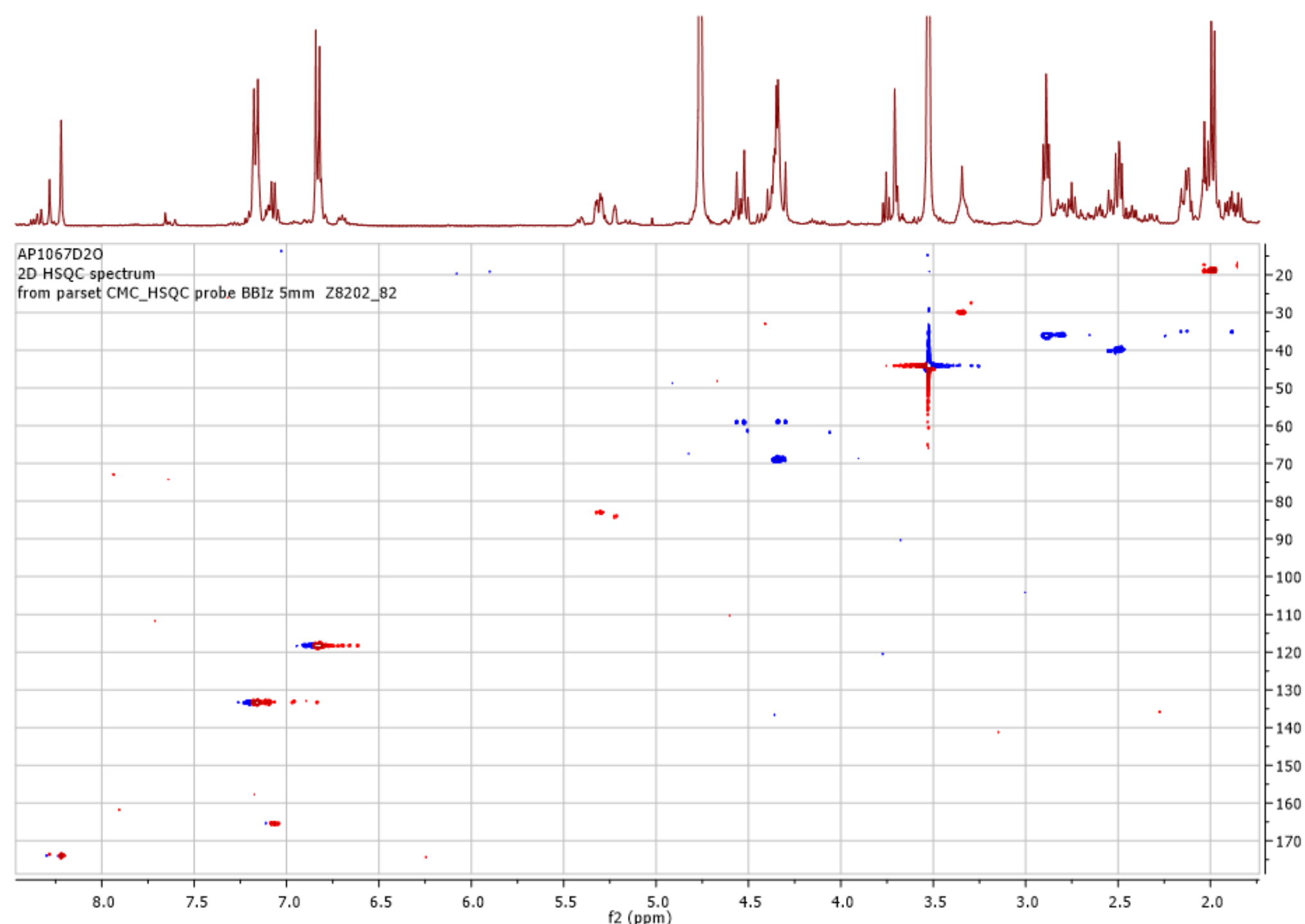

Fig. S5. HSQC-DEPT spectrum of oleoglycine (3a,b) in $\mathrm{D}_{2} \mathrm{O}$. 


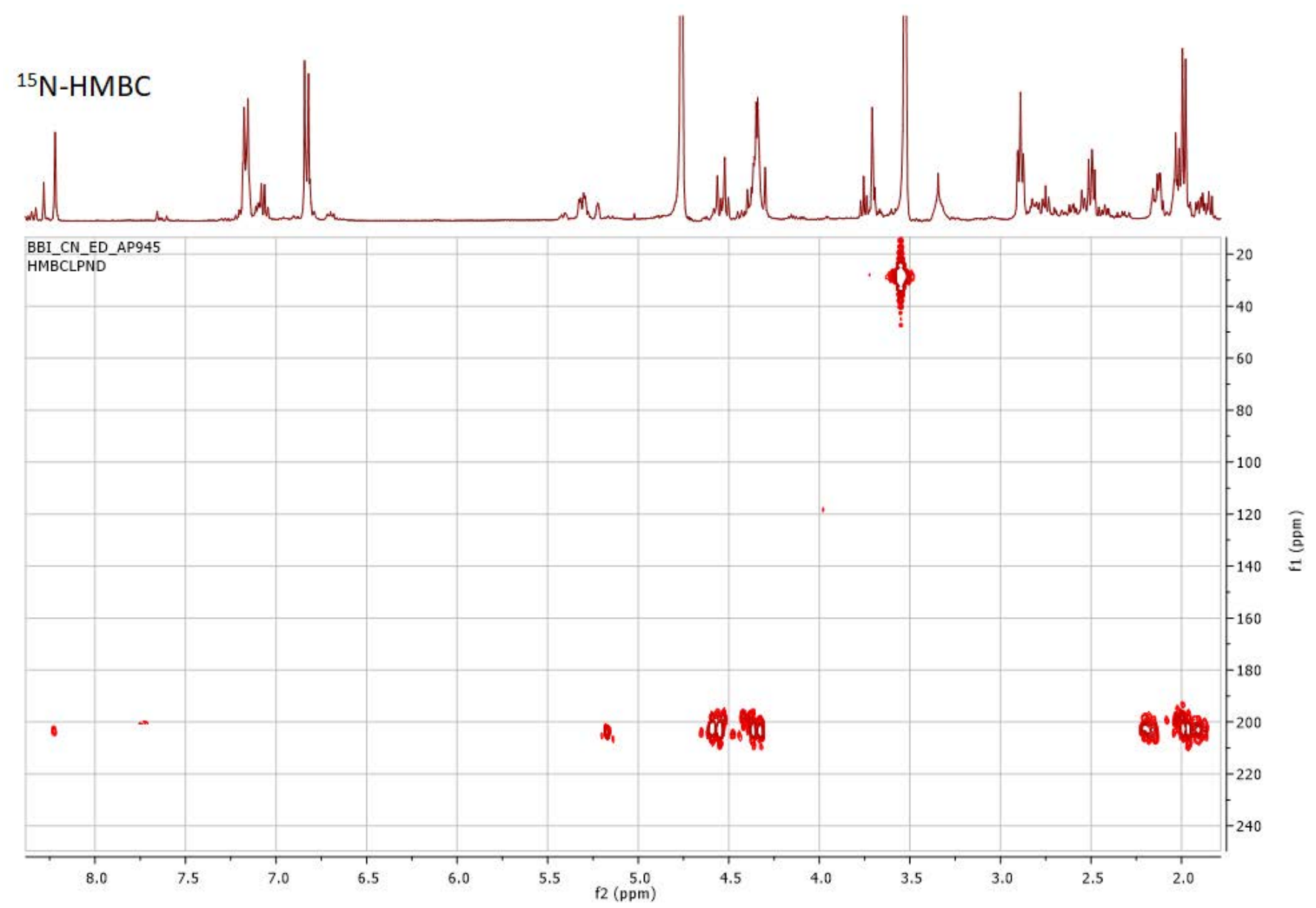

Fig. S6. ${ }^{1} \mathrm{H}^{15} \mathrm{~N}-\mathrm{HMBC}$ spectrum of oleoglycine (3a,b) in $\mathrm{D}_{2} \mathrm{O}$. 


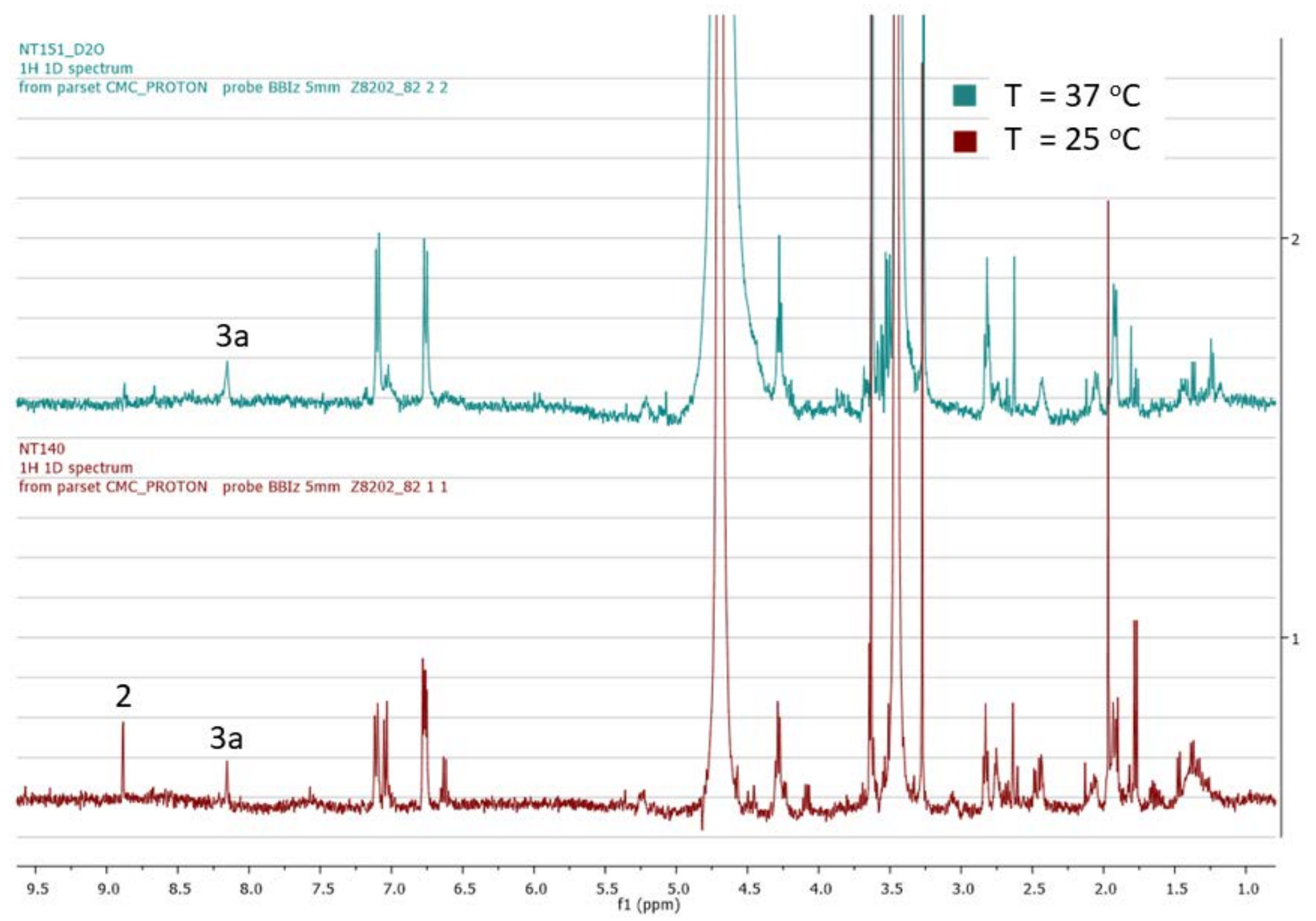

Fig. S7. ${ }^{1} \mathrm{H}-\mathrm{NMR}$ spectra of the reaction between oleocanthal $(100 \mu \mathrm{g})$ and glycine (x300) at different temperatures (25 and $\left.37^{\circ} \mathrm{C}\right)$ in $\mathrm{D}_{2} \mathrm{O}$ after $10 \mathrm{~min}$. The aldehyde peak has almost completely disappeared at $37^{\circ} \mathrm{C}$ significantly faster than at $25^{\circ} \mathrm{C}$. 


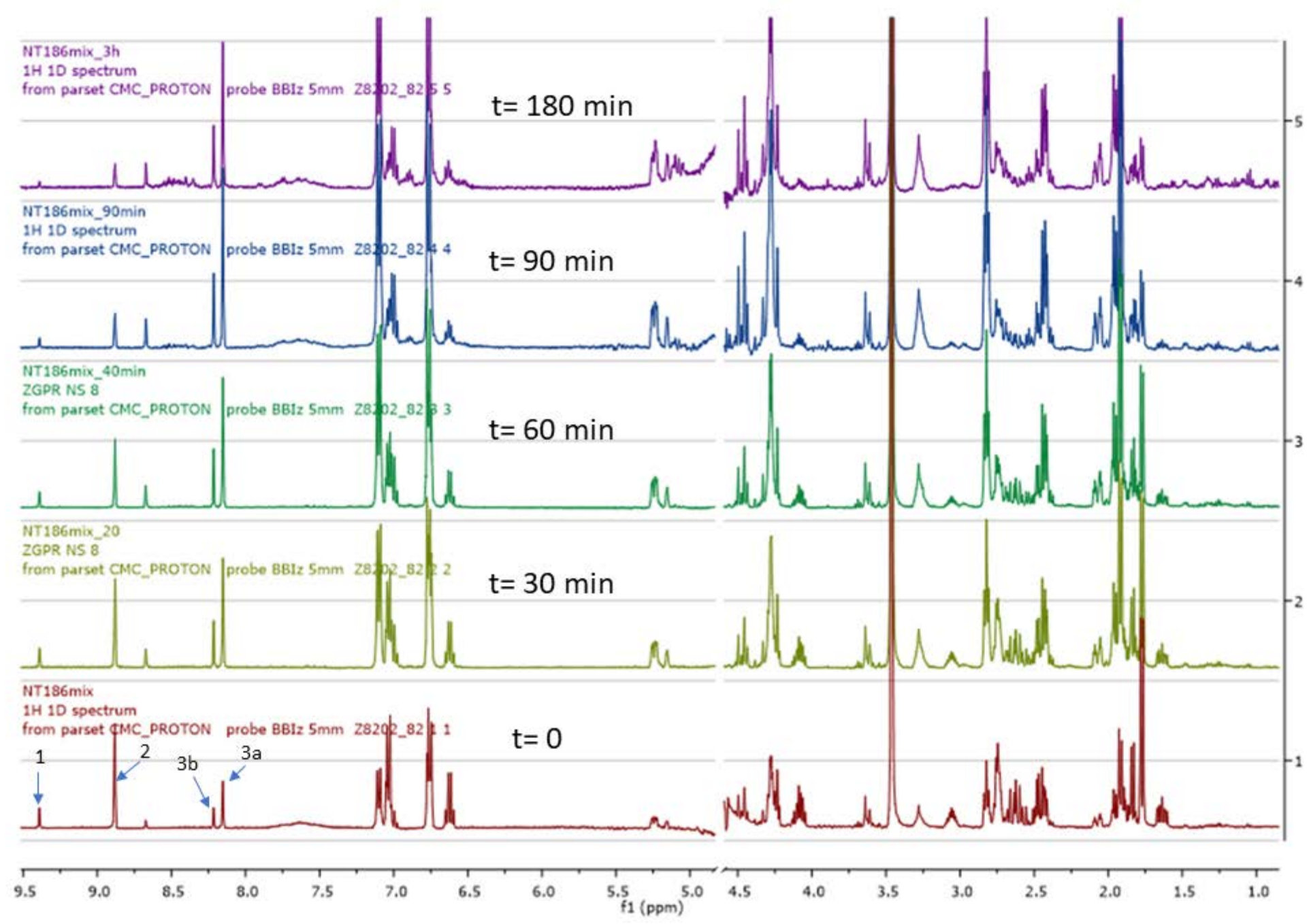

Fig. S8. ${ }^{1} \mathrm{H}-\mathrm{NMR}$ spectra of the reaction between oleocanthal and glycine (x5) at different time points in $\mathrm{D}_{2} \mathrm{O}$ at $\mathrm{pH}=2.3$. $\alpha$ and $\beta$ oleoglycine are observed based on the two proton peaks at 8.22 and $8.29 \mathrm{ppm}$. Their formation is almost completed within 90 to 180 min. 


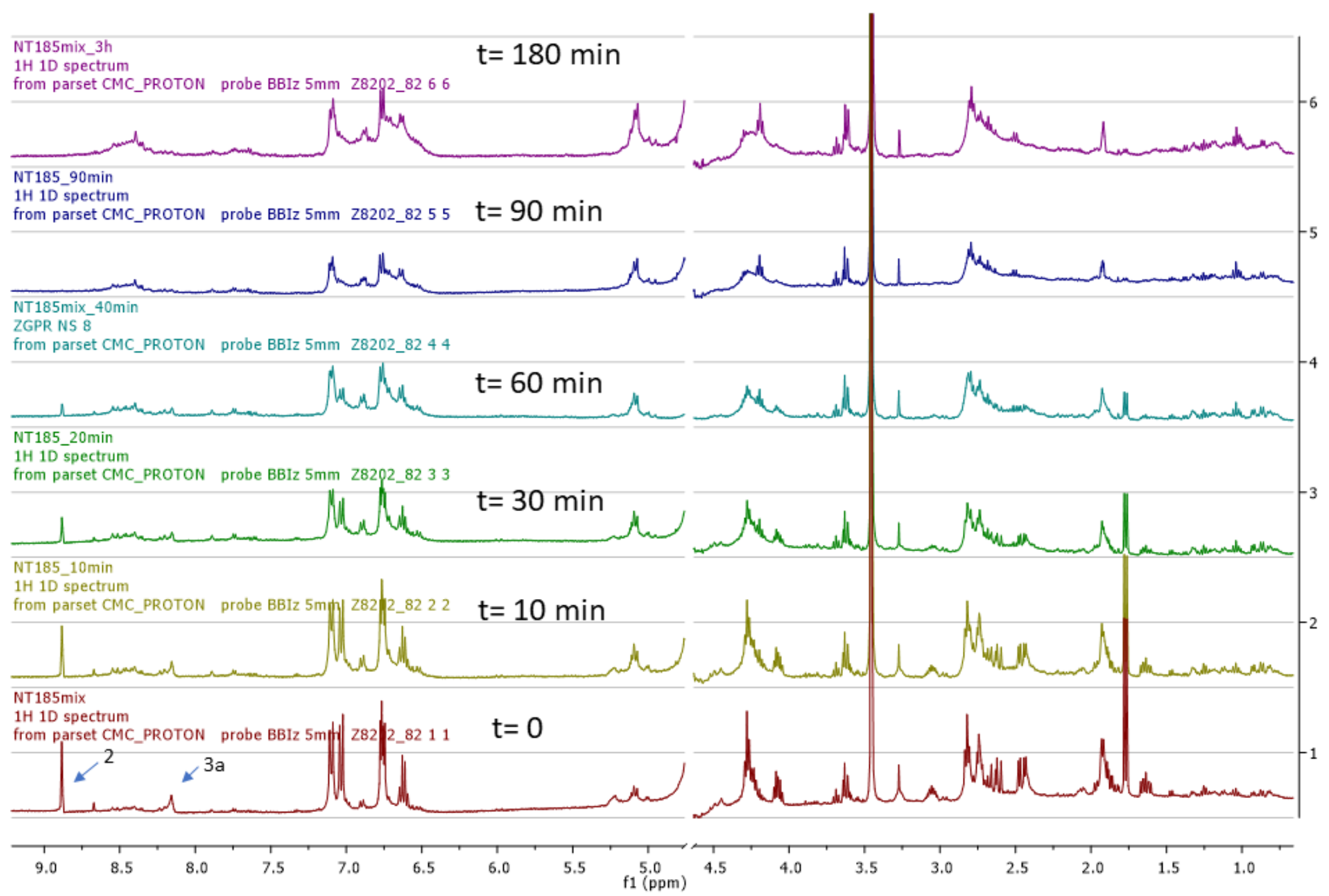

Fig. S9. ${ }^{1} \mathrm{H}-\mathrm{NMR}$ spectra of the reaction between oleocanthal and glycine $(\mathrm{x} 5)$ at different time points in $\mathrm{D}_{2} \mathrm{O}$ with $\mathrm{pH}=8.5$. The alkaline $\mathrm{pH}$ is detrimental for the formation of oleoglycine as observed from the peak at $8.22 \mathrm{ppm}$. 